\title{
A Framework for Fostering Compassionate Design Thinking During the De- sign Process
}

\section{Miss Priya Seshadri, Purdue University}

Priya Seshadri is pursuing her PhD in Mechanical Engineering at Purdue University. Prior to this, she completed MS in Mechanical Engineering at Purdue University and worked as a product engineer in the automotive industry for a year. Her research interests include design and design methodology.

\section{Dr. Tahira N Reid, Purdue University, West Lafayette}

Dr. Tahira N. Reid is currently an Assistant Professor in the School of Mechanical Engineering at Purdue University and is the director of the Research in Engineering and Interdisciplinary Design (REID) Lab. Her research interests include: developing methods to enhance the design process and that support the decision-making of engineers and designers in the design process. Prior to Purdue, she completed a postdoctoral fellowship in the Mechanical Engineering department at Iowa State working in the Interdisciplinary Research in Sustainable (IRIS) Design Lab. In 2010, she received her PhD from the University of Michigan in Design Science, with Mechanical Engineering and Psychology as her focus areas. Dr. Reid received both her BS and MS degrees in Mechanical Engineering from Rensselaer Polytechnic Institute in 2000 and 2004, respectively.

\section{Mr. Joran W. Booth, Purdue University}

Joran Booth is a graduate student at Purdue University, studying visualization and abstraction in design. 


\title{
A Framework for Fostering Compassionate Design Thinking During the Design Process
}

\begin{abstract}
Design educators in mechanical engineering departments have witnessed an evolution in the types of design problems that students prefer to address in their courses. Anecdotal evidence from discussions with colleagues indicate that over the last 30 years, projects have evolved from the design of purely mechanical systems to projects that require knowledge outside of the traditional engineering paradigm, including social sciences. These evolving interests have added complexity to the role of design educators and have revealed the limits of available design tools used in these courses; these tools are often not sufficient to support decision-making when subjective aspects of the design process are involved, such as customer preferences.

Though a number of design tools exist to assist engineers with understanding customer preferences, they do not provide the specificity needed for sensitive design contexts and require direct access to the end-user. We define sensitive design contexts as those that are perceived largely as invasive/ personal, resulting in a high degree of emotional engagement by the user, such as patients in medical environments or victims in disaster areas. The variety and complexity of design considerations to be considered are high. In the following, we will focus on "compassionate design thinking", i.e., on the role and impact of compassion during the design process. This paper presents a baseline approach for establishing a framework for compassionate design. The ultimate goal is to provide context-specific guidelines that can be used without having direct access to the end-user.
\end{abstract}

\section{Introduction}

There are several tools helping engineering designers to gather and organize custom information, including Quality Function Deployment, ${ }^{1}$ design ethnography, ${ }^{2}$ focus groups ${ }^{3,4}$ and conducting surveys. ${ }^{5}$ These methods assist with problem definition and understanding customer needs. The quality of the information gathered is directly linked to the quality of questions asked of end-users as well as the engineer's ability to make good observations and ascertain explicit or latent user needs from their interactions. Other disciplines have developed tools that can be applied to engineering design contexts. Educators in technology education introduced their students to the 'Physical, Intellectual, Emotional and Social (PIES)' instructional tool to consider user needs. ${ }^{6}$ 
User-centered design principles allow the designer to understand and integrate end-user data during the design process. Empathic design allows the engineer to identify with the challenges of the end-user by observing the user in the context of use and may also include simulating the context of the end-user for better understanding. User Experience (UX) methods were developed largely to evaluate product usability and are primarily applied to web usability contexts. Other methods, such as co-design and human centered design, also provide approaches to facilitate better understanding of the user. These methods are suitable for understanding customer needs in general contexts, but may not provide enough specificity to address design contexts that are more sensitive in nature. We define sensitive design contexts as those that are perceived as invasive/ personal by the user, resulting in a high degree of emotional engagement in the given context, such as patients in medical environments or victims in disaster areas.

Figure 1 shows an example of a problem statement provided at a sophomore level introductory mechanical design class at a mid-western university. Although the problem statement explicitly requires consideration of the emotions of the end-users, it was found that many students disregarded this aspect of the problem statement. Most likely, this was because, only tools that were suitable for managing the functional aspects of the design were provided, while the students were not given any specific tools during the lectures to help cultivate their thinking in this regard.

"Life Sustaining Devices and Systems for Protection during Threats and Disasters"

\begin{abstract}
Problem Statement
Within the last ten years alone, there have been several natural disasters (e.g. recent typhoon, tornadoes, hurricanes, earth quakes, tsunami, etc.) that have caused rapid and uncontrollable devastation, some leading to entire regions being levelled. Unfortunately, many of these disasters have led to tens of thousands of fatalities and prolonged search and rescue operations. In addition, many of the survivors have physical disabilities and require assistive devices to help them lead a somewhat normal life.

Your mechanical design firm is being consulted by a major organization seeking solutions to address future events. They need help with any of the following:

- mechanical or robotic systems that can improve search and rescue operations

- assistive medical devices for physical limitations

- rapidly deployable protective equipment that can sustain the life of survivors until they are found

The initial attributes identified for these new products include (where applicable): adjustable for use by different people, protects the entire body (most relevant for bullet 3), lightweight and portable to allow easy moving and setup, compact and/or collapsible use in smaller spaces, should clearly be a mechanical system (i.e. has motion/dynamics, electromechanical elements, etc.) and should be suitable for the terrain/ environment in which it will be used.

The products must be functional, convenient and safe. Your design must be innovative (significantly different functionality than current products) or simply be a brand new invention. It should have significant mechanical functionality, and should make efficient engineering use of materials and shapes for performance, strength and safety. The products must be functionally effective for the customers and marketplace that you help to identify and characterize. Design teams can also show how their designs can benefit other contexts outside of natural disasters.
\end{abstract}

Given the traumatic nature of natural disasters, please keep in mind the emotional states of the individuals being rescued or protected and potential physiological responses to these emotional states (i.e. trembling, stiffness, etc.). Finally, consider the following key words as teams explore various design contexts: safety, health, dignity, empowerment, and happiness.

Figure 1: Problem statement from an introductory design course

Engineers are called upon to address problems that require an understanding, not only of the technical aspects, but also of a wide range of implications, ranging from social, to economic, and psychological impacts of their design decisions, indicating the importance of non-technical skills in the professional development of engineers. ${ }^{7}$ The capacity to recognize and respond to needs or 
emotions experienced by others are valuable traits in any engineer; however, the development of this capacity is not a part of the standard engineering curriculum. ${ }^{8}$ The role of morality in design projects has also been discussed. ${ }^{9}$ Engineering education typically lacks focus on the needs of individuals, while other disciplines, in particular in the wider medical field, place more emphasis on these issues. ${ }^{10}$

In this paper, we focus on compassionate design methodology itself, rather than considering personal disposition such as emotional intelligence ${ }^{11}$ or the Big Five Factors, ${ }^{12}$ both of which describe personality and social inclinations towards certain types of thinking. We define 'compassionate design thinking' as the ability to think through, identify, and potentially implement compassion factors in the design process. 'Compassion factors' are physical or psychological design interventions that affect the interaction of the user with an artifact that involves a high level of emotional involvement on the user's part.

We propose a first step towards establishing a framework called compassionate design, with the goal of sensitizing engineers to issues and considerations that may get overlooked when relying solely on traditional methods. First, we survey the current literature on design methods (Section II). We then present an analysis of exemplary case studies and identify some emerging themes (Section III) to provide initial elements of the framework (Sections IV). Section V and VI provide insight on teaching design and conclude with an outlook on future work.

\section{Survey of the Literature: Design Thinking Methods and Philosophies}

There are a number of common, customer-oriented design methods used in design engineering. These include, but are not limited to, emotional design, user-centered design, human centered design, empathic design, and co-design. They consider different aspects of both customer and context, and provide valuable information in different ways.

\subsection{Emotional Design}

Emotional design was described by Don Norman ${ }^{13}$ as including three levels of design: visceral, behavioral, and reflective. These levels are influenced by human cognition and emotion. The visceral level assesses preferences as perceived through the senses. They are fast and automatic, often based on "gut level" reactions. Emotional design is usually based on the aesthetics (e.g., visual, auditory, etc.) of an artifact. The behavioral level is linked to the use and performance of the product (i.e., its functionality only). The reflective level is concerned with the meaning that users assign to an artifact and their relation to it. For example, the level of prestige associated with owning or using a certain product.

\subsection{User Centered Design and User Experience}

User Centered Design (UCD) is a design philosophy and approach that places the users at the center of the design process, ${ }^{14}$ where their input influences how the design takes shape. ${ }^{15}$ Users 
can be involved throughout the entire design process or during certain phases, such as determining requirements and testing. ${ }^{14,15}$ Feedback is often obtained through a number of ways, such as interviews, on-site observations, and focus groups, among others. ${ }^{16}$

User-experience (UX) was first referenced by Don Norman ${ }^{17}$ and involves considering the user's internal state (e.g. predispositions, expectations, moods, etc.), characteristics of the designed system (e.g., complexity, usability), and the context of the interaction (e.g., social setting). ${ }^{18}$ Like with other methods, the user is involved at every stage of the design process and provides the designer with first-hand feedback on the design. Once user requirements are gathered, the designer will develop a few preliminary designs. Users are then asked to evaluate the proposed design solutions and provide feedback. Continuous discussions with the users make sure that designers are aware of users' needs and/ or the context in which the artifact will be used. ${ }^{15}$ However, a noted flaw with UX methods is that they are "vague, elusive, and ephemeral". 18

\subsection{Human Centered Design}

The design of an artifact is not just about the function it provides, but also about its meaning. ${ }^{19}$ According to Krippendorf, ${ }^{19}$ human centered design methods "weave available knowledge of how meanings arise within relevant stakeholder communities into the design process in order to assure that a design encourages the meanings that lead to reliable interfaces while discouraging those that cause disruptions, disappointments, breakdowns, and harm".

"THE user" is typically the end-user who is targeted by user centered design approaches. However, the artifact actually interacts with many users other than just the end-user. Instead of an average user, "networks of stakeholders" are recognized in this design philosophy.

The following methods ${ }^{19}$ are proven approaches (amongst others) to human centered design; they include various steps:

- $(\mathrm{Re})$ designing the characters of artifacts

- Designing artifacts that are informative (expressive) of their workings

- Designing original artifacts, guided by narratives and metaphors

- Designing design strategies

- Dialogical ways to design

Human centered design focuses on the human aspect of the design and provides for the needs and experiences, both articulated and unarticulated. ${ }^{20}$ Gasson highlighted the difference between user centered and human centered approach and argues, "that "user-centered" system development methods fail to promote human interest because of a goal-directed focus on the closure of predetermined, technical problems". ${ }^{21}$

The literature on human centered design does not suggest any way of sensitizing the designer to the context in the absence of prior experience or direct contact to the respective context. 


\subsection{Empathic Design}

Empathic design is a set of techniques that helps to identify customer-needs; it has its foundation in observation of the customer in her/ his environment, that is, in the context of use. ${ }^{22}$ Leonard and Rayport ${ }^{22}$ describe the data that can be collected by observing the users utilizing the product/ service in their own environment and not in a laboratory. Useful information can be gathered about intangible attributes of the product and unarticulated user needs by observing the user and the customization done by her/ him..$^{22}$ Many such scenarios for empathic design have been described by Leonard and Rayport ${ }^{22}$ and are discussed in the paragraphs below. When the designer/engineer is observing the user's interactions with the product, they can identify intangible attributes of the product that affect the user's interaction or choice, but may not be explicitly mentioned by the user in a survey or focus group.

The steps in an empathic design process include observation, capturing data, reflection and analysis, brainstorming for solutions and developing prototypes of possible solutions. ${ }^{22}$ The observer should be someone who has expertise in a particular area such as behavioral science or ergonomics, to name a few. Users should be observed during their regular routines and not in focus groups or laboratory settings. Videos, photographs, and a list of questions for the observers themselves can help in capturing data. The team should then reflect on the data gathered in order to capture different perspectives and questions from the other team members. Brainstorming sessions can be used "to transform the observations into graphic, visual representations of possible solutions". ${ }^{22}$ Finally, developing prototypes of possible solutions helps to better understand the design concepts.

Lin and Seepersad ${ }^{23}$ performed a study with empathic lead users to find out whether the experience could uncover latent customer needs that were generally not articulated or obvious in interviews. They defined empathic lead users as "ordinary customers (or designers) who are transformed into lead users by experiencing the product in radically new ways, via extraordinary user experiences" ${ }^{23}$ The study showed that interviews with empathic lead users led to the discovery of many difficulties faced by the customers, latent needs, and potential solutions for the same. Leonard and Rayport ${ }^{22}$ describe the use of emphatic design for household detergents. The study showed that the smell of the product evoked satisfaction with a certain detergent, a feeling of nostalgia or a feeling of clean-smelling clothes, indicating certain unarticulated latent needs of the user. Another example ${ }^{22}$ describes a product developer of Hewlett Packard, who was able to identify one such hidden need while observing a surgeon performing an operation. The surgeon was watching his hands and the patient's body on a television screen and used this visual information to guide his scalpel. Although his view was getting obstructed for a few seconds when nurses were walking by, there were no complaints. The product developer addressed this unarticulated problem by a lightweight helmet that displayed the images just a few inches from the surgeon's eyes. The need of an unobstructed view while performing the operation was not mentioned by the user, but the developer was able to identify this by observing the user in her/ his environment.

Empathic design empowers designers by observation. To perform empathic design, the designer/ engineer should preferably assess the user in the natural environment of usage, which requires both time and financial resources. The competency and expertise of the designer/ engineer 
determine the quality and quantity of data (observations) gathered to a large extent. Peter Landwehr ${ }^{24}$ pointed out that empathetic design is a design process in which the designer role-plays the user to gain experience of how the user would feel in a certain context. Empathic design follows the same definition as used by Leonard and Rayport. ${ }^{22}$ It is the process of ascertaining the needs of the user by observation of the user in the context of use.

\subsection{Co-Design}

Literature review shows that there are only a few formal definitions for co-design. Sanders and Stappers $^{25}$ differentiate between co-creation and co-design. They define co-creation as "any act of collective creativity, i.e., creativity that is shared by two or more people". ${ }^{25}$ It is a broad term, not only related to design, but encompassing many other fields. Further, they define co-design as indicative of "collective creativity as it is applied across the whole span of a design process" and use "co-design in a broader sense to refer to the creativity of designers and people not trained in design working together in the design development process". ${ }^{25}$ Co-design is a process in which the user not only gives feedback and information about the product/ service, but is also an active part of the entire design process. If involved throughout the process (depending on the level of user-contribution), she/ he is a counterpart to the designer/ engineer from the user's world (not necessarily trained in technical design). The impact of co-design on the convergence of an idea from concept to product is presented in Fig. 2.

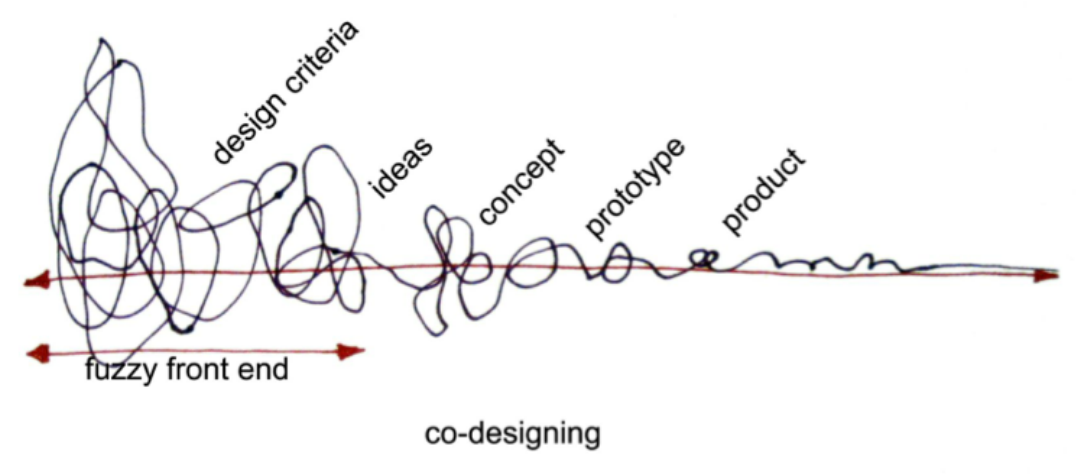

Figure 2: Co-design's impact on the design process. ${ }^{25}$

The first important phase is the so-called pre-design phase (fuzzy front end) that helps establish the design criteria, and understanding the users and contexts. Once these are established, ideas are generated and developed into concepts. Various prototypes are made and user feedback is sought, followed by an iterative process to refine the design until the final product is obtained. The differences between the role of users, researchers, and designers is illustrated in Fig. 3 by Sanders and Stappers. ${ }^{25}$ In the classical design process, the user provides information that is translated by the researcher (using theory) to the designer. In the co-design process, everybody works together, 
the user, the designer and the researcher, who is also the facilitator. He facilitates the process by leading the users and guiding them so that they can be more involved in the design process. The designer contributes the required technical skills to lead the design to execution. Sanders and Stappers ${ }^{25}$ point to the example of Nike, who is allowing people to customize their shoes, enabling the user to become a part of the design process (at a later stage of design).
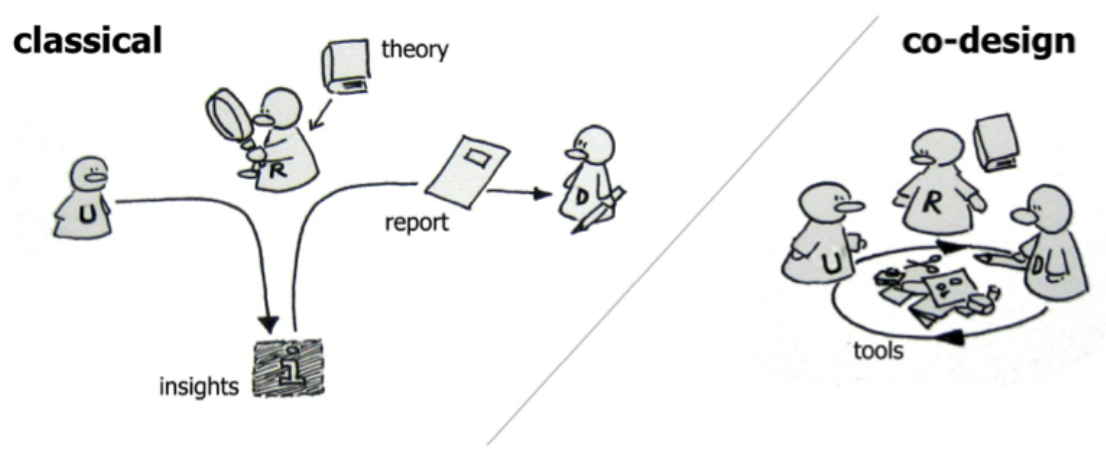

Figure 3: The role of users, researchers and designers in the classical and co-design process. ${ }^{25}$

\subsection{Summary of the Discussed Design Methods and Philosophies}

While the various design methods described earlier are distinguished by their individual characteristics, there is a lot of overlap between them. Fig. 4 provides a summary of some of the design attributes. It shows that sensitizing the designer is not always emphasized by these design methods and that most of these methods require access to the user and her/ his context. However, there are certain design scenarios in which a sensitized designer would be able to contribute to solving the design problem (such as high distress or health issues). Compassionate design will address this context space and eventually will lead to a set of guidelines that could be applied to other contexts as well and that an engineer/ designer can use if direct access to the user is limited or difficult to obtain.

\section{Analysis of Case Studies to Identify Compassion Factors}

There are many excellent examples of designers and engineers using design principles to identify hidden user needs or to improve the quality of the user experience. However, as noted earlier, some of these methods are not robust in the absence of interaction between the user and the designer. The following presents some case studies that identify elements of compassionate design thinking and compassion factors that inform our explanation of compassionate design discussed in Section 4 (see also Fig. 6). 


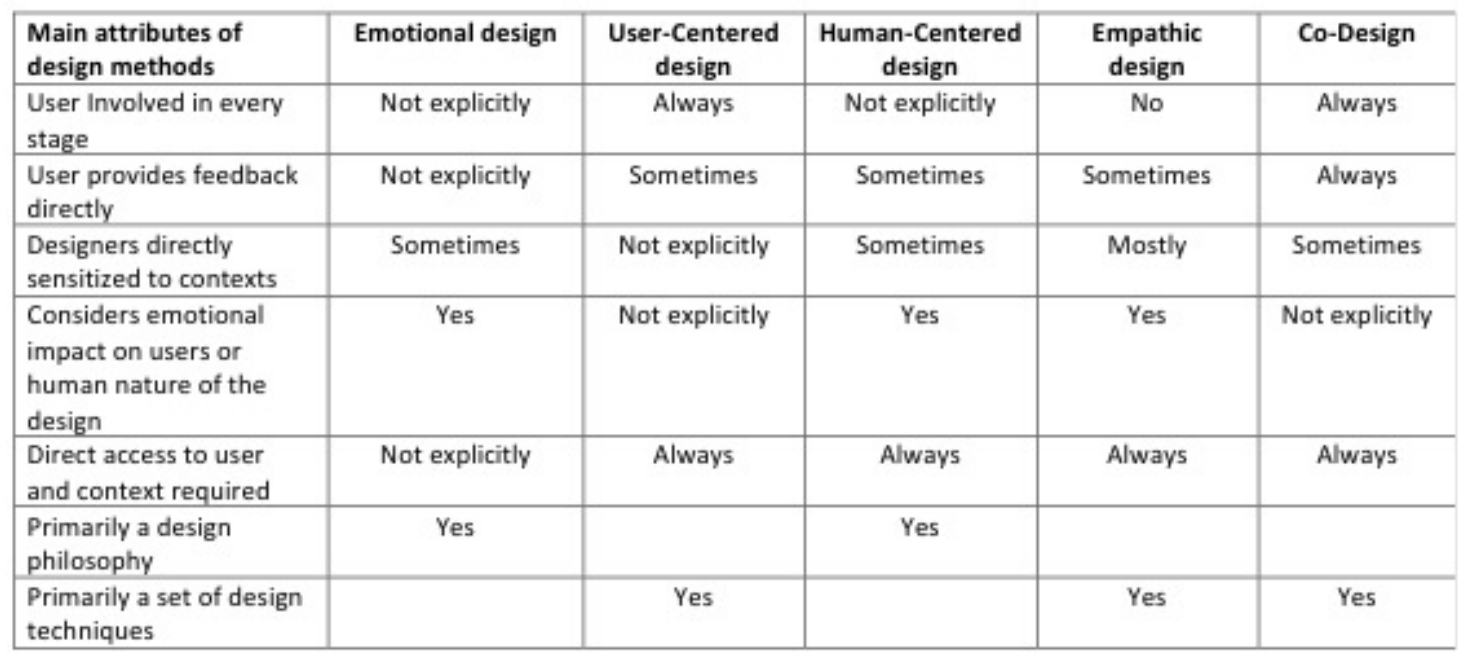

Figure 4: Main attributes of design methods and philosophies summarized

\subsection{Case Study 1: 'Embrace' baby warmer}

'Embrace' baby warmer is a device that keeps newborn babies (especially premature and low birth-weight babies that require an incubator) warm and comfortable. ${ }^{26}$ The device was designed by a group of engineers to address the needs in places where incubators are unaffordable or cannot be maintained. Existing videos and talks about 'Embrace' show that the motivation for this design solution was driven by compassion for the mothers who lose their babies because of limited access to technology that provides the conditions for the baby's survival. The engineers on this project did not only focus on solutions that work, but also considered various other factors related to the context, such as lack of or unreliable electricity, affordability, and portability. Portability was an important factor because it allowed continuous contact between the mother and the baby. In addition to other needs, this solution also addressed the emotional need of 'care' from the mother to the newborn.

\subsection{Case Study 2: 'Jaipur Foot'}

Jaipur Foot ${ }^{27}$ is a prosthetic leg for people with lower-limb amputation. This device was designed and created in cooperation of an orthopedic surgeon, Dr. P. K. Sethi, and a sculptor, Mr. Ram Chandra Sharma. They were motivated by understanding the mindset of their patients which led to low acceptance of previously used artificial limbs that looked artificial and out of place. With the sculptor's help, the prosthetic looked like a foot, in addition to being functional. ${ }^{28,29}$ This restored the patients' sense of pride; they had a chance to be independent and not feel out of place. The designers also considered the socio-economic context of their patients and provided meals and boarding to the patients free of charge. Although the user was accessible to these designers, their design incorporated compassionate elements. The fact that the foot looks like a foot and not like a prosthetic limb is a compassionate insight aimed at restoring the dignity of the users. Other designs may have been functional, inspired a sense of ownership, or otherwise been 
successful, but they neglected the far more subtle psychological need to look "normal".

\subsection{Case Study 3: 'Berkeley Darfur Stove'}

A stove for the women in Darfur, the 'Berkeley Darfur Stove', was developed by Prof. Ashok Gadgil and his team to provide the people in Darfur with more fuel-efficient ways to cook. $^{30,31,32,33,34,35}$ The intention was to reduce the risk and hardship that women were exposed to while fetching fuel wood. ${ }^{36,37,38}$ Because the design focused specifically on reducing physical or psychological harm, we consider it compassionate design.

\subsection{Case Study 4: 'UV Waterworks'}

Prof. Gadgil and his team also developed the UV WaterworksTM, which is a low-cost water disinfection system, designed for the developing world. ${ }^{39,40}$ This device was motivated by compassion for people who suffered during a cholera epidemic in India and nearby countries in 1993. ${ }^{41,42}$ This design considered low cost, use in rural areas, reliability, and low maintenance of the device as needs of the user. Compassionate design can be seen here as it addresses the needs of 'health' and 'empowerment' of people (empowered to be self-sufficient in being able to maintain the device).

\subsection{Case Study 5: GE MRI for kids}

General Electric (GE) transformed magnetic resonance imaging (MRI) scans for children into an adventure experience or journey based on children's stories, camping trips, pirate adventures, under-sea journeys, and others. ${ }^{43}$ The motivation behind this approach was compassion for the children who have to be sedated because they are too scared to go into the scan machine.

Consideration of the psychological distress that a child faces and also the needs of parents who have to convince the child to endure this medical procedure, renders this an example of how compassionate can influence design thinking.

By creating a story around the scan machine, children are distracted from the colder, more adult experience surrounding a regular MRI machine. The children were involved as a part of a story (jungle, pirate adventure, etc.) even before they entered the diagnostic room, so they were in a different mindset, far from being distressed, transforming the medical procedure into a playful fantasy story. By incorporating strategies to reduce emotional distress, the designers improved the experience for the children so much that some children even wanted to repeat the scan. This design was driven by compassion because the designer had an innate knowledge of children's needs, beyond what the children were able to express or understand. In the new machine and its environment, the subtle and unseen need was addressed by a clear, intimate understanding of the nature of children. This kind of insight is indicative of compassionate design thinking. 


\subsection{Case Study 6: 'Rabbit Ray'}

Esther Wang and her team designed 'Rabbit Ray'. a toy for children to familiarize them with certain medical equipment before they go for the actual treatment. ${ }^{44}$ The design for this device was driven by compassion for children who are scared of medical procedures and the environment in a hospital. Esther Wang explained her motivation and the use of compassion in design in a TEDx (Technology, Entertainment, Design) talk ${ }^{45}$ as an explicit attempt to introduce play and fantasy into a medical environment and familiarize children (in a latent way) with potentially distressing realities of medical practice. This type of design is compassionate because it illustrates a clear understanding of the psychological needs of children, beyond what the children can articulate.

The examples discussed here depict the influence of compassion on designers. Some of the examples also illustrated elements of human-centered, emotional, and empathetic design, because compassionate design shares elements with many of these. Engineers and industrial designers are influenced by compassion during the design process, intentionally or unintentionally, and depending on their prior experience with the context and their knowledge of the subject. We intend to define compassion factors that can be used by anyone irrespective of their prior experience or knowledge of the context.

\section{Compassionate design}

In view of the case studies, we believe that the described design solutions were not only the result of understanding the users and working with them towards a logical solution, but they were also led by strong insights of a designer who was sensitized to human needs and addressed them appropriately. This insight also required a high sensitivity to the context of use. For instance, in the case of 'Jaipur foot', even though the prosthetic limb that was preceding the new design was perfectly functional, it was not widely accepted for reasons the users did not explicitly state. The innovators of the 'Jaipur foot' were able to relate to the users. With the 'Jaipur foot', the sense of dignity, pride and feeling to be a part of society (not feeling out of place) was restored to the user. Compassionate Design is intended to provide this kind of sensitivity to the engineers or designers, irrespective of their prior experience or knowledge about the user or context. Compassionate design thinking is the ability to think through, identify, and potentially implement compassion factors in the design process. It is intended to sensitize engineers and designers to familiar and unfamiliar contexts, in which the user has a high level of emotional involvement. The targeted areas for the application of compassionate design would be contexts primarily related to emotions in the first and fourth quadrant of Fig. 5 and can be later extended to those in the second and third quadrant. 


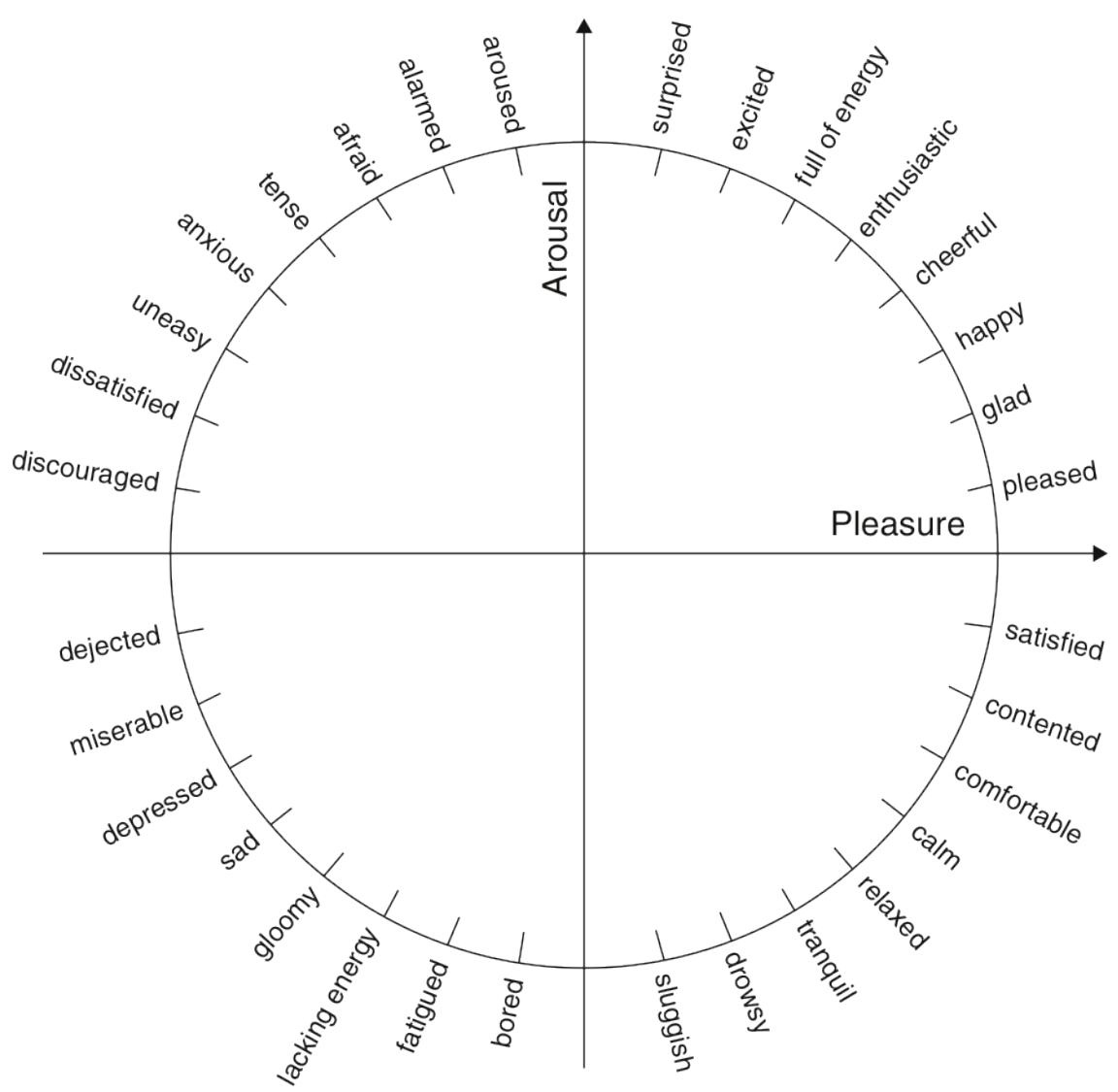

Figure 5: A two dimensional view of well-being. ${ }^{46}$

Elements of compassionate design are listed below. These elements provide the criteria to be used for thinking through and evaluating design decisions, thus leading to the establishment of the Design for Compassion (DfC) metric.

1. Reduce distress - this may be physical, psychological, social, or others.

2. Improve perceived safety - this includes ways to make the user feel safer in various situations and to reduce irrational fear.

3. Reduce danger - this includes especially dangers independent of the product itself. How do you help the user avoid or reduce exposure to dangerous situations?

4. Enhance the sense of user dignity - this means the design should enable the user to feel a sense of respect as a person. It should enhance their sense of identity and respect as a person.

5. Enhance the sense of empowerment - this means that the user should feel empowered and more in control of the situation while using the product or service.

6. Enhance health - this means the design should address the concerns of the user regarding health and make her/him feel healthier. 
7. Enhance the sense of well-being or happiness - this means the user should feel contented and happy by using the product or service.

In many contexts, these elements can be addressed using some other design methods. For example, when looking to reduce a user's distress, the techniques used by empathic design may be very useful. Also, designing to increase user dignity may be closely related to the third level of emotional design. What distinguishes compassionate design from these other methods is a designer, who is sensitized by using compassion factors during the design process, gaining insight into human nature. Another distinctive characteristic of this method is the fact that it does not depend on having access to a user, although it may still be desired.

Compassionate design focuses on sensitizing the designer about the context, the usability of the design in a certain environment with its given geographic and ethnographic resources and limitations (similar to empathic design), and the overall emotion that the user associates with a certain product or service (similar to visceral design). It starts with the motivation of compassion and targets contexts that have a high level of user involvement and affect needs of the user that fall in the following categories:

1. Dignity

2. Health

3. Empowerment

4. Safety

5. Happiness.

This approach is summarized in Fig. 6, which shows that compassionate design adapts features from principles similar to other methods; however, compassionate design is unique in its combination, scope, and priorities. 


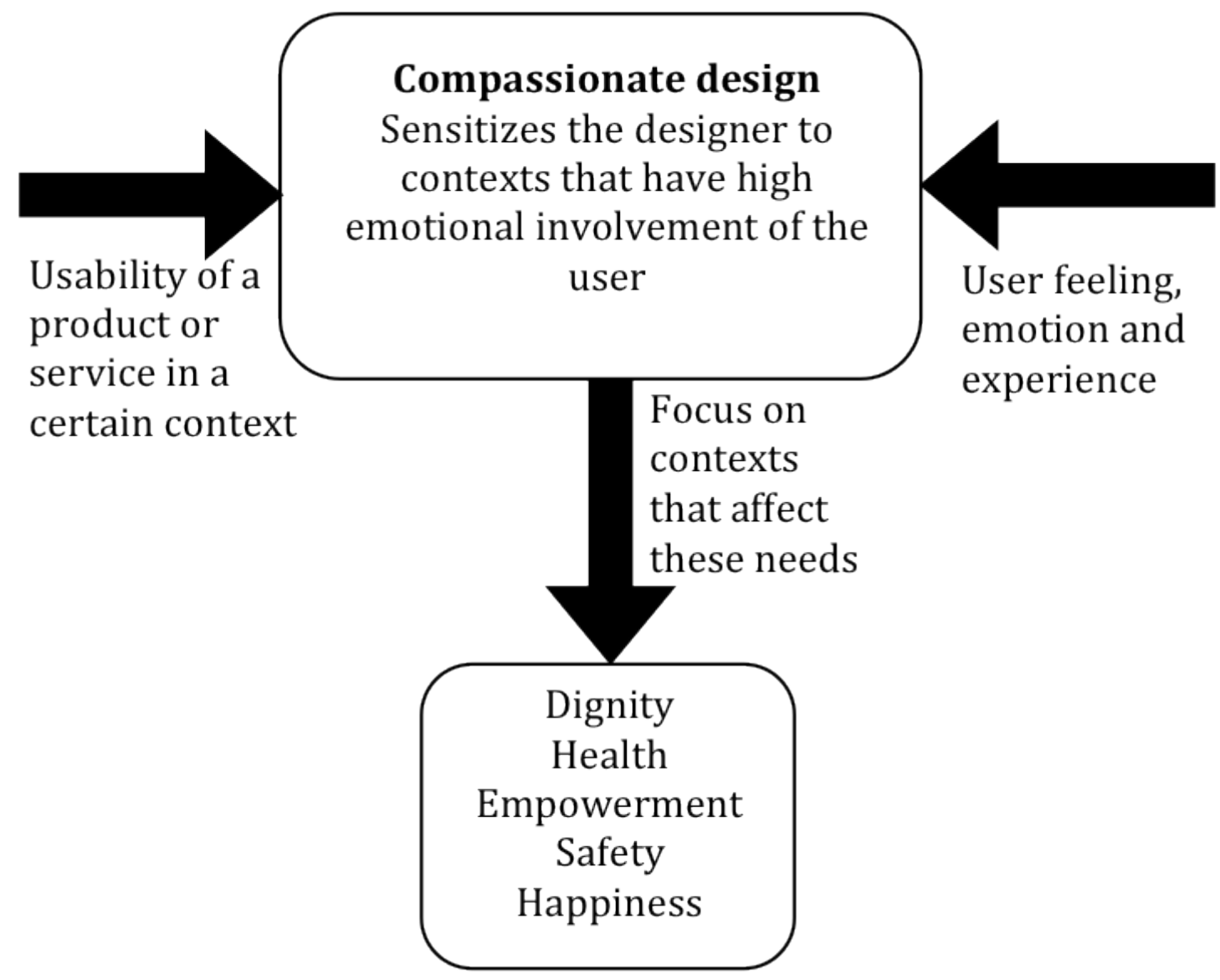

Figure 6: Elements of Compassionate Design

The case studies showed that there are some underlying criteria common to the design thinking involved in each of them. From these studies, some immerging themes were identified that provide preliminary considerations to foster compassionate design thinking (see Fig. 6).

However, in order to verify and further determine the parameters used in compassionate design thinking, the Delphi method will be employed. ${ }^{47,48,49,50,51}$ Figure 7 provides an overview of the framework that will be used to verify a preliminary list of the compassionate design parameters and/or discover more such parameters. 


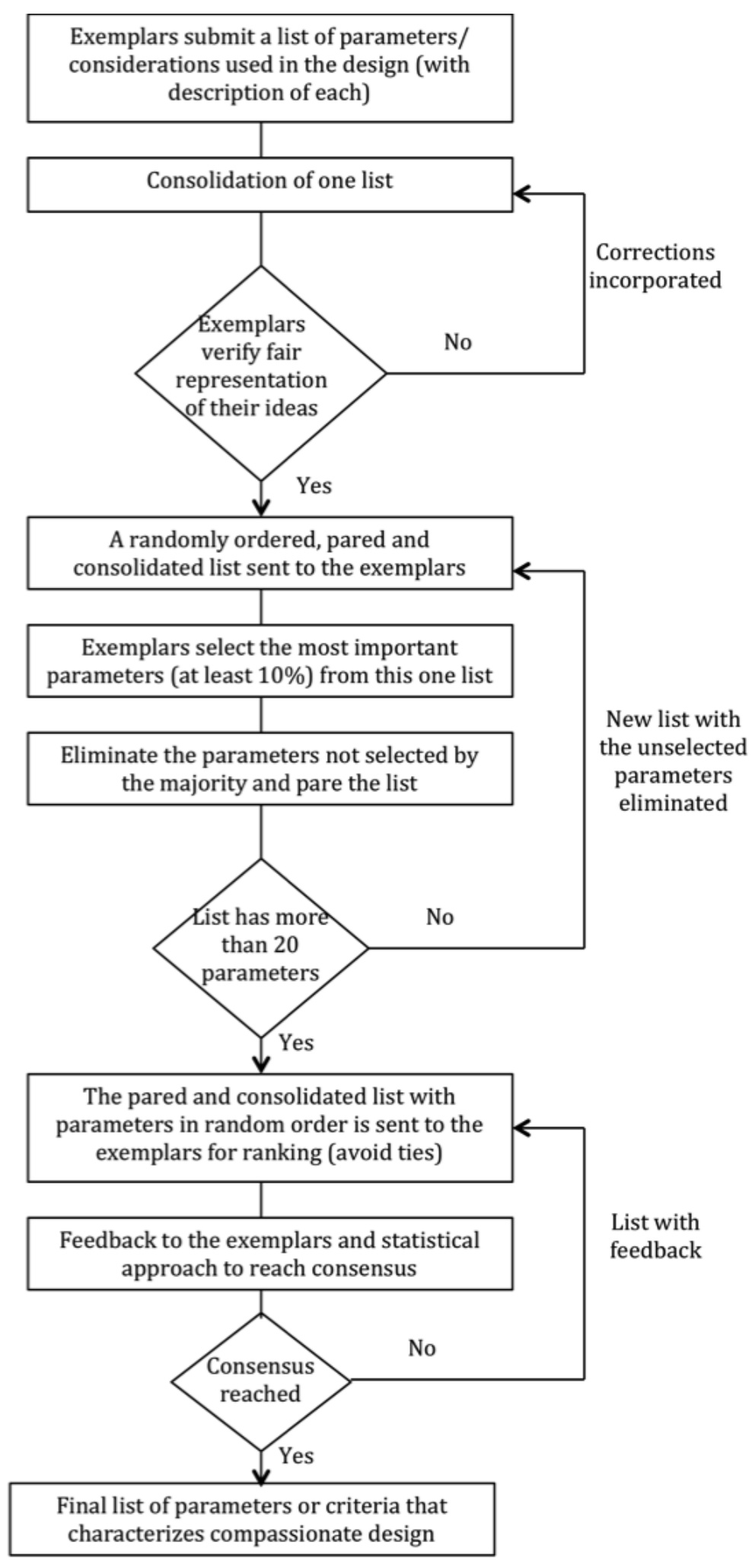

Figure 7: Framework for discovering the principles of DfC based on Delphi method ${ }^{51}$

After a list of parameters or criteria is used to characterize compassion in design, they will be 
treated as the principles behind compassionate design thinking and will form the basis of Design for Compassion. These principles are to be used while the design is in process and also to evaluate a certain design after its completion. One of the ways to evaluate a design is a radar plot based on these principles. Some compassion factors would be common to all design scenarios, whereas other compassion factors would be specific to certain design scenarios. This will be validated by further studies. These design scenarios can be broadly grouped into basic categories by the use of cluster analysis: ${ }^{52}$

1. Basic needs

2. Medical treatment and health

3. Safety

4. Developing economies

5. General or everyday objects

There would be a few principles or parameters that are common to all these groups and a few that are specific to a group. The final intention is to develop a metric (using these principles) that helps the engineer or designer to use compassion while thinking, designing and also during evaluation.

\section{Teaching Design and Incorporating Compassionate Design Thinking}

To illustrate how compassionate design thinking could be used in practice, we present an example. One of the most challenging problems in developing countries is that the fact electricity is not available to a majority of the population. People often have to use natural light in order to complete their daily tasks. Imagine that a team of engineers or designers were tasked with providing light to households so that typical household tasks could be completed after sunset. Direct experience and interaction with the end-user would provide useful insights on the nuances of this context. However, time and resources may limit the engineers'/ designers' ability to gain such direct access. The engineers/designers could then conduct research through secondary sources, gateway interviews, and rely on experiences and common sense. However, it is possible that some of the emotional aspects of the context may get overlooked. The compassionate design metric is intended to contribute to such a situation, where the engineer can use the metric and become aware of and sensitive to the context without having to interact with the user. This situation would require the engineer to think about the feelings of a family who is facing difficulties as food cannot be prepared, children cannot complete their home-work, and they cannot afford a power generator. The compassionate design metric is designed to help the engineer address this kind of situation.

After a more formalized approach for compassionate design has been developed, it is planned to incorporate it into design courses. Teaching compassionate design thinking to novice engineers will help to provide specific ways of thinking while performing engineering design tasks, thus enhancing their knowledge foundation and the ability to critically think through open-ended problems. Once elements of compassionate design have been made an integral part of 
engineering education, more fundamental knowledge about this design approach will be developed and subsequently find entrance into the design paradigm.

Currently, there are little to no formal methods available to help sensitize engineers to design contexts that require a more in-depth assessment of the deeper needs of the end-user. The need for care and empathy has been acknowledged as a valuable contribution to engineering education, ${ }^{8}$ yet there is a need for an integral approach to transfer this insight to engineering students and instill this desirable skill set in future engineers. This skill set is especially valuable in medical design contexts. We believe that including compassionate design in the teaching curriculum at a stage when the students are first being introduced to design will make compassionate design a part of the whole process and not a separate add-on. This approach may influence the way future engineers will think about design and use design thinking.

\section{Conclusion and Future Work}

The various existing design thinking methods support different aspects of the design process. Compassionate design thinking is intended to sensitize the engineer or designer to contexts in which the users exhibit high emotional involvement. Compassionate design thinking describes the ability to think through, identify, and potentially implement factors based on compassion in the design process. The authors envision that, once compassionate design principles are uncovered more fully, a compassionate design metric can be developed and used during the design process and also for the evaluation of completed design projects.

Future work includes the establishment of a method to quantify compassion factors, which may be subjective in nature. To explore the role of personality and how it may impact the implementation of the metrics, a series of experiments would be conducted to evaluate the natural disposition of an engineer to use compassion in the design process. It could also lead to the discovery of new principles and verify elements of the metric. We envision that compassionate design thinking will enhance the design process, which will lead to improved user satisfaction and added meaning of the artifact to the user. It will also provide a tool that design educators can implement in the classroom to better support design projects where a focus on functionality is insufficient. In turn, engineers will gain experience with a formalized method for providing design solutions that probe thinking that keeps sensitive aspects of the user context in mind.

\section{References}

${ }^{1}$ Yōji Akao. Quality function deployment: integrating customer requirements into product design. Productivity Press, 1990.

${ }^{2}$ Sasha A. Barab, Michael K. Thomas, Tyler Dodge, Kurt Squire, and Markeda Newell. Critical design ethnography: Designing for change. Anthropology and Education Quarterly, 35(2):254-268, 2004. 
${ }^{3}$ Karl T. Ulrich and Steven D. Eppinger. Product Design and Development. McGraw Hill New York, NY, 2000.

${ }^{4}$ Anne Bruseberg and Deana McDonagh-Philp. Focus groups to support the industrial/product designer: a review based on current literature and designers' feedback. Applied Ergonomics, 33(1):27 - 38, 2002.

${ }^{5}$ David G. Ullman. The Mechanical Design Process. McGraw Hill New York, NY, 2010.

${ }^{6}$ D. Barlex. Curriculum development. In P. John Williams, editor, Technology Education for Teachers. Sense Publishers, Netherlands, 2012.

${ }^{7}$ Kathleen H Sienko, Amir Sabet Sarvestani, and Lonny Grafman. Medical device compendium for the developing world: a new approach in project and service-based learning for engineering graduate students. Global Journal of Engineering Education, 15(1), 2013.

${ }^{8}$ Johannes Strobel, Justin Hess, Rui Pan, and Carrie A. Wachter Morris. Empathy and care within engineering: qualitative perspectives from engineering faculty and practicing engineers. Engineering Studies, 5(2):137-159, 2013.

${ }^{9}$ C.P. Titus, Carla B. Zoltowski, and William C. Oakes. Work in progress - assessing moral decision making skills in the engineers of 2020. In Frontiers in Education Conference (FIE), 2010 IEEE, pages S3E-1-S3E-2, 2010.

${ }^{10}$ Donia R Baldacchino. Teaching on spiritual care: the perceived impact on qualified nurses. Nurse education in practice, 11(1):47-53, 2011.

${ }^{11}$ Peter Salovey and David J Sluyter. Emotional development and emotional intelligence: Educational implications. Basic Books, 1997.

12 J M Digman. Personality structure: Emergence of the five-factor model. Annual Review of Psychology, 41(1):417-440, 1990.

${ }^{13}$ Donald A. Norman. Emotional design: Why we love (or hate) everyday things. Basic books, 2007.

${ }^{14}$ Eun-Ok Baek, Kursat Cagiltay, Elizabeth Boling, and Theodore Frick. User-centered design and development. Handbook of research on educational communications and technology, pages 659-670, 2008.

${ }^{15}$ Chadia Abras, Diane Maloney-Krichmar, and Jenny Preece. User-centered design. Bainbridge, W. Encyclopedia of Human-Computer Interaction. Thousand Oaks: Sage Publications, 37(4):445-456, 2004.

${ }^{16}$ Jennifer Preece, Yvonne Rogers, and Helen Sharp. Interaction design: beyond human-computer interaction. New York, NY: John Wiley and Sons, 2002.

${ }^{17}$ Don Norman, Jim Miller, and Austin Henderson. What you see, some of what's in the future, and how we go about doing it: Hi at apple computer. In Conference companion on Human factors in computing systems, page 155. ACM, 1995.

${ }^{18}$ Marc Hassenzahl and Noam Tractinsky. User experience - a research agenda. Behaviour Information Technology, 25(2):91-97, 2006.

${ }^{19}$ Klaus Krippendorff. On the essential contexts of artifacts or on the proposition that "design is making sense (of things)". Design Issues, 5(2):9-39, 1989.

${ }^{20} \mathrm{~J}$. Giacomin. What is human centred design. In 10th Conference on Design Research and Development, PDesign, São Luís, pages 10-13, 2012.

${ }^{21}$ Susan Gasson. Human-centered vs. user-centered approaches. Journal of Information Technology Theory and Application, 5(2):29-46, 2003.

22 Dorothy Leonard and Jeffrey F Rayport. Spark innovation through empathic design. Harvard business review, 75:102-115, 1997.

${ }^{23}$ Joseph Lin and Carolyn Conner Seepersad. Empathic lead users: the effects of extraordinary user experiences on customer needs analysis and product redesign. In ASME DETC Design Theory and Methodology Conference, 2007. 
${ }^{24}$ Peter Landwehr. Empathic design vs. empathetic design: A history of confusion, 2007.

${ }^{25}$ Elizabeth B-N Sanders and Pieter Jan Stappers. Co-creation and the new landscapes of design. Co-design, 4(1):5-18, 2008.

${ }^{26}$ Embrace Innovations. http://www.embraceinnovations.com/.

${ }^{27}$ P. K. Sethi, M.P. Udawat, S.C. Kasliwal, and R. Chandra. Vulcanized rubber foot for lower limb amputees. Prosthetics and Orthotics International, 2(3):125-136, 1978.

${ }^{28}$ BBC Film on Jaipur Foot, Part 1. http://www.youtube.com/watch?v=UCr3NEciDTA.

${ }^{29}$ BBC Film on Jaipur Foot, Part 2. http://www.youtube.com/watch?v=5pGqj51-XPU.

${ }^{30}$ Susan Amrose. Development and testing of the berkeley darfur stove. Technical report, Lawrence Berkeley National Laboratory, http://escholarship.org/uc/item/3rf3x1df, 02-29-2008 2008.

${ }^{31}$ Christina Galitsky, Ashok Gadgil, Mark Jacobs, and Yoo-Mi Lee. Fuel efficient stoves for darfur camps of internally displaced persons-report of field trip to north and south darfur, nov. 16-dec. 17, 2005. Technical report, LBNL, 2006.

${ }^{32}$ Allan Chen. A mission to darfur. Science at Berkely Lab, page 3, 2006.

${ }^{33}$ Ashok Gadgil and Susan Amrose. Darfur fuel-efficient-stoves (fes). Lawrence Berkeley National Laboratory (LBNL), 2006

${ }^{34}$ Ashok J Gadgil, Ken P Chow, Howdy Goudey, et al. Fuel efficient portable stove for use with a round-bottom pot, April 14 2009. US Patent D590,202.

${ }^{35}$ Berkeley Lab Cookstove Projects (Darfur). http://cookstoves.lbl.gov/darfur.php.

${ }^{36}$ Erin Patrick. Sexual violence and firewood collection in darfur. Forced Migration Review, 27:40-41, 2007.

${ }^{37}$ Darfur Stoves Project - KQED QUEST. http://www.youtube.com/watch?v=c-yFSfafHhc.

${ }^{38}$ Ashok Gadgil - Darfur Stoves. http://www.youtube.com/watch?v=PnIUdOOUgo4.

${ }^{39}$ A. Gadgil, David Greene, Anushka Drescher, Peter Miller, and Ndirangu Kibata. Low-cost ultraviolet disinfection system for developing countries. Providing Safe Drinking Water in Samall Systens: Technology, Operations, and Economics, page 165, 1999.

${ }^{40}$ Ashok Gadgil. Safe and affordable drinking water for developing countries. In AIP Conference Proceedings, volume 1044, page 176, 2008.

${ }^{41}$ Lemelson-MIT (Inventor of the Week Archive). http://web.mit.edu/invent/iow/gadgil.html.

${ }^{42}$ Ashok Gadgil on the LBNL Institute for Globally Transformative Technologies (LIGTT). http://eetd.lbl.gov/news/article/11823/ashok-gadgil-on-the-lbnl-institute-for-globally-transformative-technologiesligtt.

${ }^{43}$ GE fmri. http://www.youtube.com/watch?v=nPlvBPtxEl4.

${ }^{44}$ Rabbit Ray from Joytingle. http://joytingle.com/.

${ }^{45}$ Rabbit Ray TEDx talk. http://www.youtube.com/watch?v=TaYA1sKobYk.

${ }^{46}$ Warr P. Well-Being: Foundations of Hedonic Psychology, chapter Well-Being and the Workplace, pages $392-412$. Russell Sage Foundation, New York, 1999.

${ }^{47}$ Harold A. Linstone and Murray Turoff. The delphi method. Addison-Wesley Reading, MA, 1975.

${ }^{48}$ Norman Dalkey and Olaf Helmer. An experimental application of the delphi method to the use of experts. Management Science, 9(3):pp. 458-467, 1963. 
${ }^{49}$ Norman Crolee Dalkey, Bernice B Brown, and Samuel Cochran. The Delphi method: An experimental study of group opinion, volume 3. Rand Corporation Santa Monica, CA, 1969.

${ }^{50}$ Chitu Okoli and Suzanne D. Pawlowski. The delphi method as a research tool: an example, design considerations and applications. Information Management, 42(1):15-29, 2004.

${ }^{51}$ Roy C. Schmidt. Managing delphi surveys using nonparametric statistical techniques*. Decision Sciences, 28(3):763-774, 1997.

${ }^{52}$ Leonard Kaufman and Peter J. Rousseeuw. Finding groups in data: an introduction to cluster analysis, volume 344. Wiley. com, 2009. 